\title{
MODIFICATION OF THE TONUS AND DRUG-INDUCED CONTRACTION OF THE ISOLATED RAT ILEUM BY REMOVAL OF Na FROM BATHING MEDIA
}

\author{
Kohtaro TANIYAMA \\ Department of Pharmacology, Kobe University School of Medicine, \\ Ikuta-ku, Kobe, Japan
}

Accpted November 14, 1973

\begin{abstract}
Effect of removal of $\mathrm{Na}$ from bathing media on the tonus and contractile response to drugs of strips of the rat ileum was investigated. Removal of Na from the bathing media by replacing $\mathrm{NaCl}$ with sucrose or choline $\mathrm{Cl}$ produced a transient contraction, which was not altered by treatment with atropine. This contraction was attenuated when preparations were exposed to Ca-free media. After a $30 \mathrm{~min}$ exposure to $\mathrm{Na}^{+}$-free media, contractions causcd by $\mathrm{ACh}$ and $\mathrm{Ba}$ and the phasic contraction by $\mathbf{K}$ were decreascd, whereas the tonic contraction by $\mathbf{K}$ was increased. In preparations in which contractions by removal of $\mathrm{Na}^{+}$were abolished by repeated treatments with $\mathrm{Na}^{+}$-removal in $\mathrm{Ca}$-free media, the contractions were restored when the preparations were incubated with $\mathrm{Ca}^{++}$and then with $\mathrm{Na}^{+}$-containing solutions. This restoration was not obtained when preparations were soaked in Na-frec media after incubation with $\mathrm{Ca}^{++}$. It appears that removal of $\mathrm{Na}$ from bathing media inhibits uptake of $\mathrm{Ca}$ by intracellular storage sites and increases the influx of $\mathrm{Ca}^{++}$, resulting in an increase in the amount of cellular active $\mathrm{Ca}^{++}$, and that $\mathrm{Na}^{+}$plays an important role in binding $\mathrm{Ca}^{++}$in intracellular storage sites.
\end{abstract}

During the past decade numerous studies on interactions of extracellular $\mathrm{Na}$ with $\mathrm{Ca}$ responsible for mechanical activities of smooth muscles have accunulated. It is generally agreed that in various organs and animal species reduction in extracellular $\mathrm{Na}$ elicits an increase in inward movements of Ca across cell membranes (1-5). However, little information $(6,7)$ is available concerning the effect of reduced $\mathrm{Na}$ on the contractility of intestinal smooth muscles. The present study includes findings showing that removal of Na from bathing media not only increases the influx of $\mathrm{Ca}$ into muscle cclls but also accelerates the release of $\mathrm{Ca}$ from intracellular storage sites.

\section{MATERIALS AND METHODS}

Male rats, weighing approx. $300 \mathrm{~g}$, werc uscd. The animals were sacrificed by a blow on the neck and the ileum was dissected. Strips of the ileum, approx. $1 \mathrm{~cm}$ long, were fixed vertically in the preparation bath containing $30 \mathrm{ml}$ of nutrient solutions. IsoIonic contractions were recorded on a smoked paper with a magnification of approx. 10 times. The solution was maintained at $27.0 \pm 1.0^{\circ} \mathrm{C}$ and continuously bubbled with air. The composition of the solution was as follows $(\mathrm{mM}) ; \mathrm{NaCl}, 154 ; \mathrm{KCl}, 5.6 ; \mathrm{CaCl}_{2}, 2.2$;

* This study was presented at the Kinki Regional Meeting 41 of the Japancse Pharmacological Society, in Hiroshima, June 4, 1972. 
glucose, 5.6; $\mathrm{NaHCO}_{3}, 4.8$. In the $\mathrm{Na}$-free solution used, $\mathrm{NaCl}$ was replaced with isotonic sucrose or choline $\mathrm{Cl}$. When Ca was totally removed, osmotic adjustment was not made. Preparations were allowed to equilibrate for 60 to $90 \mathrm{~min}$ in bathing solutions before experiments were begun.

Acetylcholine chloride (Tokyokasei), barium chloride (Wakojunyaku) and l-isoproterenol hydrochloride (Proternol-L, Nikkenkagaku) were used. Drugs were added directly to the bathing medium. Concentrations of the drug are cxpressed in terms of $\mathrm{g} / \mathrm{ml}$ of the salts. Concentrations used were $10^{-6} \Lambda \mathrm{Ch}, 10^{-4} \mathrm{Ba}$ and $2 \times 10^{-3} \mathrm{~g} / \mathrm{ml} \mathrm{K}$, which were obtained as $E_{50}$ in an earlier report (8).

\section{RESULTS}

\section{1) Effect of the removal of Na from bathing media}

When $\mathrm{NaCl}$ in the bathing media was replaced with sucrose, a transient contraction appeared, and a return to the initial tonus was usually observed about $30 \mathrm{~min}$ later. This contraction was reproducible at an interval of 20-30 min and was strongly inhibited by a pre-application of $10^{-7}$ isoproterenol, in all of 7 cases (Fig. 1). A similar contraction was produced when $\mathrm{NaCl}$ was replaced with choline $\mathrm{Cl}$. The transient contraction induced by Na removal was reduced by $24.6 \pm 2.5 \%(\mathrm{~N}-7)$ by removal of $\mathrm{Ca}^{1+}$ from bathing solutions. In the Ca-free media the contraction gradually decreased by repeated treatments with $\mathrm{Na}$ removal and within 4 hr disappeared completely.

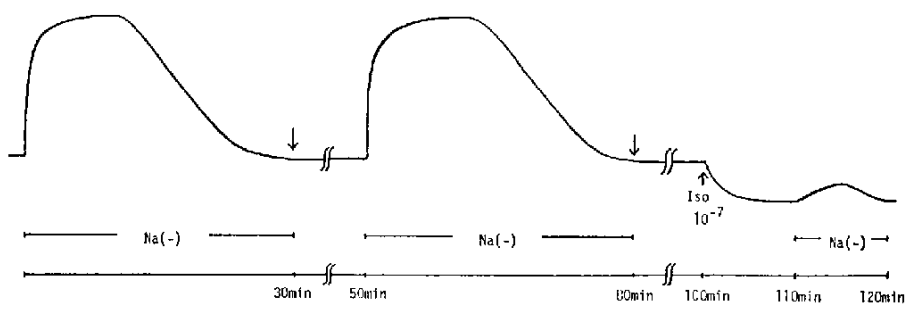

F1c. 1. Effect of isoproterenol (Iso) on the contractile response to removal of $\mathrm{Na}$ from bathing media.

$\downarrow$ : Washout with the normal medium.

\section{2) Modification by Na removal of the effect of exogenous $C a$}

The addition of $\mathrm{Ca}$ in concentrations of $2 \mathrm{mM}$ or higher always revealed a relaxation in the normal fluid but a contraction in the Na-free media. The Ca-induced contraction was reduced by $39.8 \pm 3.3 \%(\mathrm{~N}-10)$ after 30 min exposure to $\mathrm{Na}^{+}$-free media, as compared with that after 10 min cxposure (Fig. 2).

In preparations in which $\mathrm{K}$-induced contractions were abolished by repeated additions of $\mathrm{K}$ in Ca-free solutions, the addition of $2 \mathrm{mM} \mathrm{Ca}$ to Ca-free media produced a contraction. This contraction was potentiated by $35.7 \div 4.9 \%(\mathrm{~N}=6) 1 \mathrm{~min}$ after removal of $\mathrm{Na}$ from the Ca-free media. The effect of $\mathrm{Na}$ removal was reversed by washing preparations with normal solutions. 


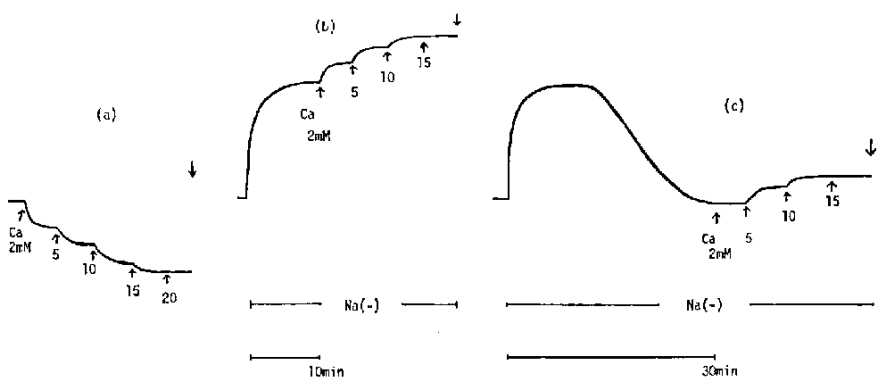

FrG. 2. Effect of exogenous $\mathrm{Ca}$ on the tonus. (a), normal bathing medium ; (b), 10 min after removal of Na from the normal bathing medium; (c), 30 min after. $\downarrow$ : Washout with the normal medium.

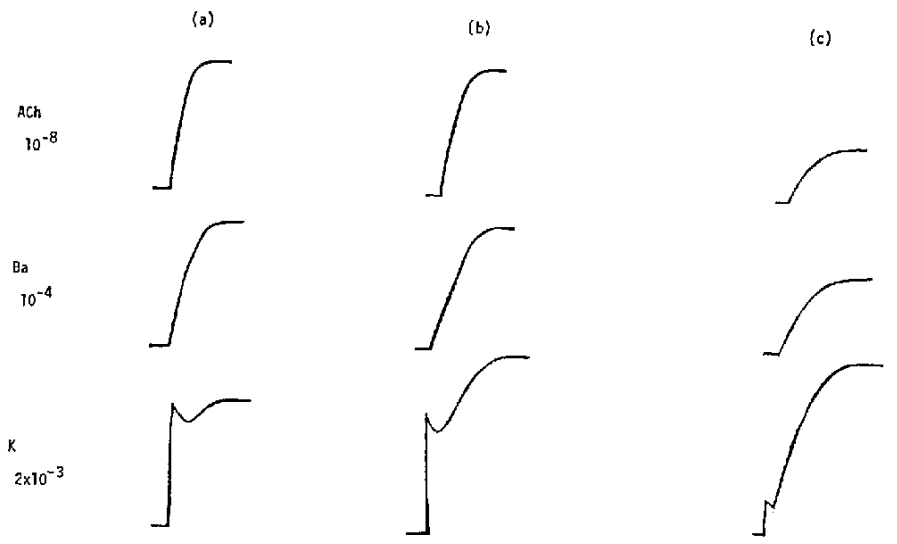

FIG. 3. Effect of Na removal from the normal bathing medium on the contractile response to stimulating agents. (a), normal bathing medium; (b), one min after $\mathrm{Na}$ removal from the normal bathing medium; (c), 30 min after.

3) Modification by Na remoral of the contractile response to various agents

The addition of $\mathrm{K}\left(2 \times 10^{3} \mathrm{~g} / \mathrm{ml}\right)$, ACh $\left(10^{-8} \mathrm{~g} / \mathrm{ml}\right)$ and $\mathrm{Ba}\left(10^{4} \mathrm{~g} / \mathrm{ml}\right)$ to the bathing media caused a rapidly-developing contracion (phasic contraction) followed by slow contraction (tonic contraction). In the contractile responses to $\mathrm{ACh}$ and $\mathrm{Ba}$ the phasic and tonic phases could not actually be distinguished. The contractions by these agents were not significantly influenced I min after removal of $\mathrm{Na}$ from the bathing media except that the conic contraction by $\mathrm{K}$ increased by $21.5+2.1 \%(\mathrm{~N}=-6)$, as compared with that in the normal media. Thirty min after removal of $\mathrm{Na}$, the contractions by $\mathrm{ACl}$ and $\mathrm{Ba}$ and the phasic contraction by $\mathrm{K}$ were inhibited by $61.1 \pm 4.9 \%(\mathrm{~N}=6), 34.7+2.2 \%(\mathrm{~N}=6)$ and $83.4+3.7 \%(\mathrm{~N}=11)$, respectively, whereas the tonic contraction by $\mathrm{K}$ was increased by $21.0 \pm 2.8 \%(\mathrm{~N}=11)$ (Fig. 3). These changes in the drug action were completely reversed within 20 min after returning preparations to the normal medium.

4) Restoration of the response to removal of $\mathrm{Na}^{+}$

Preparations in which the contraction by $\mathrm{Na}$ removal had disappearcd by repeated 


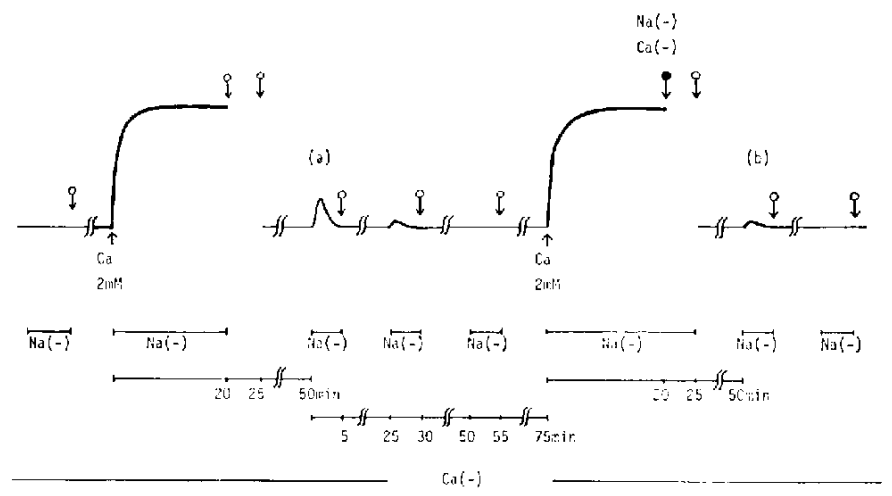

Fis. 4. Reappearance of the response to $\mathrm{Na}$ removal by the addition of $\mathrm{Ca}$. and $I$ indicate the washout with $\mathrm{Ca}(-), \mathrm{Na}(1)$ and $\mathrm{Ca}(-), \mathrm{Na}(-)$ bathing medium, respectively. Note the difference in the solution by which the preparation was washed.

treatments with $\mathrm{Na}$ removal in Ca-free media, were used. The addition of $2 \mathrm{mM} \mathrm{Ca}$ to the $\mathrm{Ca}$-free, $\mathrm{Na}$-free media produced sustained contraction. After 20 min incubation with $\mathrm{Ca}^{++}$the preparations were incubated for $30 \mathrm{~min}$ with the $\mathrm{Ca}$-free, Na-normal solution. In these preparations the contractile response to removal of $\mathrm{Na}$ was restored. A typical example of this series of experiments is shown in Fig. 4-(a). When $\mathrm{Na}$ removal from the media was repeated at $25 \mathrm{~min}$ interval, this contraction was gradually reduced. However, after subsequent treatment for $20 \mathrm{~min}$ with $2 \mathrm{mM} \mathrm{Ca}^{++}$, the contractile response to $\mathrm{Na}$ removal was again restored. Regardless of whether the time of incubation with $2 \mathrm{mM}$ $\mathrm{Ca}^{++}$was 20 or $25 \mathrm{~min}$, the contractile response to removal of $\mathrm{Na}$ was the same.

After incubation for $20 \mathrm{~min}$ with $2 \mathrm{mM} \mathrm{Ca}^{++}$, the preparations were treated for $5 \mathrm{~min}$ with Ca-free, Na-free solutions, instead of Ca-free, Na-normal solutions in the above-mentioned series of experiments, and then for $25 \mathrm{~min}$ with $\mathrm{Ca}$-frec, Na-normal solutions. Following this treatment, contractile response to removal of $\mathrm{Na}^{\prime}$ was slightly restored (Fig. 4-(b) ) $(20.0 \pm 1.9 \%(\mathrm{~N}=4)$ relative to that obtained in the above-mentioned series of experiments, as demonstrated in Fig.4-(a)).

\section{DISCUSSION}

The present study demonstrated that the removal of $\mathrm{Na}$ from bathing media by replacing $\mathrm{NaCl}$ with isotonic sucrose produced contractions in rat excised ileum, which persisted for approx. $30 \mathrm{~min}$. Since this contraction was not influenced by treatment with atropine, cholinergic mechanisms would not be involved. When $\mathrm{NaCl}$ was replaced with choline $\mathrm{Cl}$ in the presence of atropine, similar contractions were obtained, which persisted for approx. $15 \mathrm{~min}$. Thus, it can be considered that the induced contractions are due to a reduction of extracellular $\mathrm{Na}$ but not to decreased $\mathrm{Cl}$.

The contraction induced by removal of $\mathrm{Na}$ was significantly reduced in preparations exposed to Ca-free solutions. This finding supports the hypothesis that removal of $\mathrm{Na}$ from the bathing media increases the inward movement of $\mathrm{Ca}$ responsible for the smooth 
muscle contraction. It has been demonstrated that $\mathrm{Na}$ and $\mathrm{Ca}$ share channels of the cell membrane through which these ions enter into cells $(9,10)$. Thus, lowering extracellular $\mathrm{Na}$ may increase the permcability of membranes for $\mathrm{Ca}$. In addition, reduced $\mathrm{Na}$ would incrcase the $\mathrm{Na}$ efflux-Ca influx coupling system and decreases the $\mathrm{Na}$ influx-Ca efflux coupling system, as suggested in mesenteric artery and aorta (5), vascular smooth muscle (1, 12), cardiac muscle (11) and giant axon (13). In guinea pig taenia coli (14) and guinea pig taenia caecum (7), removal of $\mathrm{Na}$ from bathing media produces depolarization, probably resulting in increased influxes of $\mathrm{Ca}$, as does a membrane-depolarizing ion, $\mathrm{K}$. On the other hand, contractions by removal of $\mathrm{Na}$ were not completely abolished by treatment of preparations with Ca-free media. In preparations in which K-induced contractions were abolished by repeated additions of $\mathrm{K}$ in Ca-free media, the $\mathrm{Na}$ removal still caused contractions. Contractions induced by $\mathrm{Na}$ removal were greatly inhibited by treatment with isoproterenol, which had been suggested to selectively attenuate the release of $\mathrm{Ca}^{\text {:t }}$ from storage sites (8). These results suggest that contractions by removal of $\mathrm{Na}$ are due partly to the release of $\mathrm{Ca}$ from intracellular storage sites and that the release occurs from. not only the site sensitive to $\mathrm{K}$ but also that resistant to the ion. Possible importance of $\mathrm{Na}$ in binding $\mathrm{Ca}$ in storage sites will be discussed later.

In $\mathrm{Ca}$-depleted preparations in which contractions by $\mathrm{Na}$ removal were abolished by repeated treatments with $\mathrm{Na}$ removal in $\mathrm{Ca}$-free solutions, the contractile response to removal of $\mathrm{Na}$ was restored following incubation in $2 \mathrm{mM} \mathrm{Ca}$ and then for $5 \mathrm{~min}$ in $\mathrm{Na}$-normal, Ca-free media. Thus, addition of $\mathrm{Ca}$ appears to replenish $\mathrm{Ca}$ in intracellular storage sites. However, when the preparations were incubated for $5 \mathrm{~min}$ in Na-free, Ca-free media after treatment with $\mathrm{Ca}$, the response to $\mathrm{Na}$ removal was restored only slighlly. These findings indicate the importance of the presence of $\mathrm{Na}^{+}$in the bathing media to replenish and bind $\mathrm{Ca}$ in the storage sites. According to Arora (15), an increase in intracellular $\mathrm{Na}$ accelerates the uptake of intracellular $\mathrm{Ca}$ by storage sites in toad atria. If this applies also to the case of intestinal smooth muscles used in the present study, it can be considered that removal of $\mathrm{Na}$ from the bathing media decreases intracellular $\mathrm{Na}$, resulting in release of $\mathrm{Ca}$ from storage sites and inhibition of $\mathrm{Ca}$ from rc-binding in the sitcs and that the ability of binding $\mathrm{Ca}$ in storage sites is restored by raising $\mathrm{Na}$ in bathing media, possibly as a result of an increase in intracellular Na.

Acknowledgrement: Gratiude is extended to Prof. Hiroshi Matsumoto for kind direction during the research and assistance with preparation of this report.

\section{REFERENCES}

1) Briggs, A. And Melvin, S.: Am. J. Physiol. 201, 365 (1961)

2) Bohr, D.F.: Pharmacol. Rev, 16, 85 (1964)

3) Baker, P.F.: J. Physiol. 192, 43P (1967)

4) Prasado, K.: Can. J, Physiol. Pharmacol. 48, 241 (1970)

5) Sitrin, M.D. AND Bohr, D.F.: Am. J. Physiol. 220, 1124 (1971)

6) Karaki, H., Urakawa, N. and Ikeda, M. : Japan. J. Pharmacol. 16, 423 (1966)

7) TAKagl, K. ANd TAkAyanagi, I.: Japan. J. Pharmacol. 21, 129 (1971)

8) Taniyama, K.: Kobe J. Med. Sci. 19, 67 (1973) 
9) Wilbrandr, W. and Koller, H.: Helv. Physiol. Pharmac. Acta 6, 208 (1948)

10) Lïttgau, H.C. and Niedergfrke, R.: J. Physiol. 143, 486 (1958)

11) Reuter, H. AND Shitz, N.: $J$. Phyidol. 195, 451 (1968)

12) Bohr, D.F., Seidel, C. Aind Sobifski, J.: Microvaserular Res. 1, 335 (1969)

13) Bakek, P.F., Blaustein, M.P., Hopokn, A.I. a.td Steinhardt, R.A.: J. Physiol, 200, 431 (I969)

14) Bülbrixg, E. And Kuriyana, H.: J. Physiol. 166, 29 (1963)

15) Arora. H.R.K.: Am. J. Physiol. 222, 333 (1972) 